\title{
ULTRASONOGRAPHIC EVALUATION IN EARLY DIAGNOSIS OF INFANTILE HYPERTROPHIC PYLORIC STENOSIS
}

\author{
SAHA GC ${ }^{1}$, BISWAS PK ${ }^{2}$, UDDIN MN ${ }^{3}$, HOSSAIN ${ }^{4}$, JAHAN NWB ${ }^{5}$, KHATUN MH ${ }^{6}$, AHMED \\ $\mathrm{MZ}^{7}, \mathrm{CHOWDHURY} \mathrm{AH}^{8}$
}

\begin{abstract}
Background: Infantile hypertrophic pyloric stenosis (IHPS) is a common cause of gastric outlet obstruction in infants. This study was conducted to identify the accuracy of ultrasonography in the diagnosis of infantile Hypertrophic pyloric Stenosis.

Methods: This cross-sectional descriptive. Study was conducted in Department of radiology and imaging, institute of child and mother health during two year period from $16^{\text {th }}$ September 2016 to $16^{\text {th }}$ September 2018.

Fifty patients $<8$ weeks of age who presented with complaints of non-bilious vomiting were included in the study. Abdominal ultrasound was performed in all the cases. On ultrasonography pyloric canal length, diameter and pyloric muscle wall thickness was measured. Open surgery was performed as per indications and after informed consent. The pre-operative findings were compared with ultrasongraphic findings. Study variable were male to female ratio, percentage of cases in which pyloric mass was palpable. We also compare the duration of onset of symptoms with pyloric canal length, diameter and muscle thickness.

Results: In this study, out of 50 patients, 46 (92\%) were male and 4 (8\%) were females. Gastric peristalsis was visible in 100\% patients and mass was palpable in 14 (28\%) patients. Pyloric canal length was more than standard in 98\% cases; canal diameter was more than the standard in $87 \%$ cases and pyloric muscle thickness in $60 \%$ of cases. Ultrasonographic findings remained 98\% accurate in this study.

Conclusion: Ultrasonography is an investigation of choice for early diagnosis of IHPS before significant fluid and electrolyte imbalance occur. It is cost effective, harmless, freely available and easier to perform.
\end{abstract}

J Dhaka Med Coll. 2019; 28(2) : 208-211

\section{Introduction}

Hypertrophic pyloric stenosis (HPS) is actually idiopathic hypertrophy and hyperplasia of the circular muscle fibers of the pylorus with proximal extension into the gastric antrum. Infantile hypertrophic pyloric stenosis (IHPS) is a common cause of gastric out let obstruction in infants. Prevalence of infantile hypertrophic pyloric stenosis ranges from 1.5 to 4.0 per 1000 live births among whites but is less common in Africans, Americans and Asians. IHPS was first described two hundred years ago but still exact cause is poorly understood. ${ }^{1}$ Pyloromyotomy first described by Remsteadt in 1912 is still accepted as curative operation of choice without any modification. ${ }^{2}$ Non bilious vomiting is the initial symptom of the disease. During clinical examination, Palpable olive in the right hypochondrium or epigastrium is diagnostic. Jildi S mention in his study that pyloric tumor was palpable in $19.7 \%$ patient's only. ${ }^{3}$ Barium study helps in diagnosis of IHPS by showing

1. Dr. Gopal Chandra Saha, Assistant Professor, Institute of child and Mother Health, Matuail, Dhaka

2. Dr. Prodip Kumar Biswas, Associate Professor, Department of Medicine DMC,

3. Dr. Md. Nasir Uddin, Associate Professor, Department of Clinical Biochemistry, National Institute of Cardiovascular Disease \& Hospital, Dhaka Department of Biochemistry, NICVD, Dhaka,

4. Dr. Sahadat Hossain, Assistant Professor, OSD, DGHS

5. Dr. Nur-Wa-Bushra Jahan, Assistant Professor, department of Obstetrics \& Gynaecology, Sir Salimullah Medical College \& Mitford hospital, Dhaka

6. Dr. Mst. Habiba Khatun, Associate Professor, Department of Radiology and Imaging, BSMMU, Dhaka

7. Dr. Md. Zobaer Ahmed, Indoor Medical Officer, Department of Medicine, DMCH

8. Dr. A H Chowdhury, Associate Professor of Clinical Neurology, DMCH

Correspondence : Dr. Gopal Chandra Saha, Assistant Professor, Institute of child and Mother Health, Matuail, Dhaka Email-drgopalcs@gmail.com Cell no-01711315850

Received: 12-11-2019

Revision: 17-11-2019

Accepted: 20-12-2019 
delayed gastric emptying string sign or double track sign. ${ }^{4}$

Ultrasonography is useful, noninvasive and accurate technique to diagnose infantile hypertrophic pyloric stenosis. Ultrasonography is freely available everywhere. Most commonly used criteria for positive ultrasound study is pyloric muscle wall thickness $4 \mathrm{~mm}$ or more and pyloric canal length $16 \mathrm{~mm}$ or more. Lamaki Mentioned in his study muscle wall thickness $3 \mathrm{~mm}$ or more as positive finding for IHPS in infants less than 30 days of age ${ }^{5}$. Different criteria have been mentioned in different studies. In our study. We tried to establish diagnostic criteria in our setting by comparing ultrasonographic and operative findings.

\section{Material and methods}

This was a cross sectional descriptive study, conducted at department of radiology and imaging, institute of Child and Mother Health, Matuail, Dhaka during two years period from $16^{\text {th }}$ September 2016 to $16^{\text {th }}$ September 2018. Fifty patients $<8$ weeks of age were included in the study who come to radiology department during this time period with complains of nonbilious vomiting. Abdominal ultrasonography was done in all patients $5 \mathrm{MHZ}$ linear probe in Xario 100 Toshiba machine. On ultrasonography canal length, diameter and pyloric wall thickness were measured. Following criteria was selected for the diagnosis of IHPS on ultrasonography.

- Pyloric canal length $16 \mathrm{~mm}$ or more

- Pyloric canal diameter $14 \mathrm{~mm}$ or more

- Pyloric muscle wall thickness: $3 \mathrm{~mm}$ or more.
The patient diagnosed as IHPS on ultrasonography were considered for surgery. The surgical finding of each patient were compared with the ultrasonographic findings and assessment was made regarding conformity of surgical with ultrasonography findings.

\section{Result}

A total of 50 patient were admitted during the study period with complains of non bilious vomiting. Out of fifty, $46(92 \%)$ were male and $4(8 \%)$ were female. All the patients were above 2 weeks of age. One was between 3-4 weeks, 15 $(30 \%)$ were between 3-4 weeks, $14(28 \%)$ between 4-5 weeks, 10 (20\%) between 5-6 weeks and $10(20 \%)$ above the age o6 weeks. Table-1 shows duration of vomiting at presentation and table -2 shows comparison of duration of vomiting and pyloric canal length. Diameter and muscle wall thickness. Pyloric canal length was more than the standard in 98\%, canal diameter in $87 \%$ and pyloric muscle thickness in $60 \%$ cases. Ultrasound findings were confirmed preoperatively and found to be $98 \%$ accurate in this study.

Table-I

Duration of vomiting at presentation $(N=50)$.

\begin{tabular}{lcc}
\hline Duration of vomiting & Patients & $\%$ age \\
\hline 1 week & 15 & $30.0 \%$ \\
2 weeks & 15 & $30.0 \%$ \\
3 weeks & 5 & $10.0 \%$ \\
4 weeks & 10 & $20.0 \%$ \\
5 weeks & 1 & $02.0 \%$ \\
6 weeks & 4 & $08 \%$ \\
\hline
\end{tabular}

Table - II

Comparison of duration of vomiting and pyloric canal length, diameter and muscle thickness $(N=50)$

\begin{tabular}{lcccc}
\hline $\begin{array}{l}\text { Duration of } \\
\text { vomiting }\end{array}$ & (n) & $\begin{array}{l}\text { No of patients } \\
\text { with +ve canal } \\
\text { length (\% age) }\end{array}$ & $\begin{array}{c}\text { No of patients with } \\
\text { +ve pyloric canal } \\
\text { diameter (\% age) }\end{array}$ & $\begin{array}{c}\text { No of patients with } \\
\text { +ve pyloric muscle } \\
\text { thickness (\% age) }\end{array}$ \\
\hline 1 week & 15 & $15(93 \%)$ & $10(67 \%)$ & $2(13 \%)$ \\
2 weeks & 15 & $15(100 \%)$ & $12(87 \%)$ & $7(47 \%)$ \\
3 weeks & 5 & $5(100 \%)$ & $5(100 \%)$ & $4(80 \%)$ \\
4 weeks & 10 & $10(100 \%)$ & $10(100 \%)$ & $10(100 \%)$ \\
$>4$ weeks & 5 & $5(100 \%)$ & $5(100 \%)$ & $5(100 \%)$ \\
\hline
\end{tabular}




\section{Discussion}

A total 50 patients were included in this study who presented with the complaint of non bilious vomiting. Out of $50,92 \%$ were male and $8 \%$ were female with sex ratio $11.5: 1$ where as Assefa ${ }^{6}$ mentioned in his study total 39 patients with male to female ratio of $12: 1$, Doyel ${ }^{7}$ mention male to female ratio of 4.06: 1 in his study and Jerzy Niedziel $\mathrm{sKi}^{8}$ mentioned ratio of 8.6:1. Babies of different age groups came to our unit with pyloric stenosis during the study period. No patient was below the age of 2 weeks. Maximum number (58\%) of patients was between 3-5 weeks of age and $20 \%$ patients were above 6 weeks of age. Haahr ${ }^{9}$ mentioned in his study of 147 patients that $70 \%$ patients were 1-4 weeks of age and 28\% between 5-12 weeks of age. Jerzy Niedzielski ${ }^{8}$ mentioned median age of 40 days (range 13-111 days) and Doyle $D^{7}$ mentioned median age of weeks (range 1-8 weeks) respectively in their studies.

In our study we noticed early presentation of the patients. Thirty patients $(60 \%)$ come to our hospital with 1-2 weeks duration of non bilious vomiting whereas 4 patients came with 6 weeks history of vomiting. During examination, only in $28 \%$ patients, palpable pyloric tumor was found in our study which was comparable to $19.7 \%$ mentioned by jildi $\mathrm{S}^{1}$ in his study.

The criteria which Keller et $\mathrm{al}^{10}$ used for positive ultrasound study was pyloric mass thickness o $4 \mathrm{~mm}$ or more and pyloric canal length of 16 $\mathrm{mm}$ or more.

In this study, we studied relationship between duration of vomiting and ultrasonographic findings in IHPS like pyloric canal length, diameter and pyloric muscle thickness. Changes occur in pyloric canal length compared with duration of vomiting. Fifteen patients came with 1 weeks duration of vomiting, Among these 14 had positive pyloric canal length $(16 \mathrm{~mm}$ or more), 15 patients came with 2 weeks duration of vomiting and all had positive pyloric canal length (100\%). Five patients came with 3 weeks duration of symptoms and $100 \%$ were positive for pyloric canal length, Similarly 10 patients came with 4 weeks duration of vomiting and 5 with duration of more than 4 weeks and all were positive for pyloric canal length. It showed that pyloric canal length became positive very early in case of IHPS. So We can diagnose IHPS in very early stage with the help of ultrasonography.

Tamura and Nagea ${ }^{11}$ showed same criteria in their study to diagnose IHPS by ultrasonography.

Diameter of pylorus was compared with duration of vomiting. Fifteen patients came with 1 week duration vomiting and pyloric diameter on ultrasound was found to be positive in $10(66.6 \%)$. In patients with duration of vomiting 2 weeks. Pyloric diameter was $100 \%$ positive in patients who came with the history of vomiting for 3 weeks or more. It showed that pyloric canal diameter had intermediate sensitivity in early detection of IHPS.

In our study, we also compared the duration of vomiting and pyloric muscle wall thickness. Fifteen patients came with 1 week duration of vomiting and pyloric muscle thickness was positive only in 2 patients $(13.3 \%)$. Similarly 7 out of 15 patients (46.6\%) were having positive pyloric muscle thickness who presented with 2 weeks duration of vomiting. In patients with 3 weeks duration of vomiting, rate of positive muscle thickness was $80 \%$ ( 4 out of 5), 4 weeks duration of vomiting, rate of positive muscle thickness was $100 \%$ (5out of 5). It showed that pyloric muscle thickness is least important in early detection of disease as compared to the pyloric canal length.

\section{Conclusion}

Ultrasonography is the investigation of choice for early diagnosis of IHPS before significant fluid and electrolyte imbalance occur. It is cost effective, harmless, freely available and easier to perform. Pyloric canal length and diameter are more specific for the diagnosis of IHPS than pyloric muscle thickness.

\section{References}

1. Beard sley H. Congenital hypertrophic stenosis of the pylorous. Arch Pediatr. 1985;75:359.

2. Ramstedt C, Zur Operation der angeborenen pylorus stenose. Med klinik 1912;8:1702-5.

3. Jildi S, Ben Youssef D, Ghorbel S, Mattoussi N, Khemakhem R, Nouira F, et al. Infantile hypertrophic pyloric stenosis. Reprt of 142 cases. Tunis Med 2008; 86:63- 7 . 
4. Rddan-Valadez E, Solor Zano-Morales S, Osorioperalta S. Imaging diagnosis of infantile hypertrophic pyloric stenosis. Report of a case and review of the literature. Rev Gastroenteral Mex. 2007; 72: 126-32.

5. Lamaki N, Athey PA, Round ME, Watson AB Jr, Pfleger MJ. Hypertrophic pyloric stenosis in the neonate, Diagnostic.

6. Assefa G, Sonographic diagnosis of hypertrophic pyloric stenosis. Prediminary experience. Ethiop Med J 2002;40:149-54.

7. Doyle D, O'Neil M, Kelly D. Changing trends in the management of infantile hypertrophic pyloric stenois an audit over 11 years. In J Med Sci 2005;174:33-5.
8. Niedzielski J, Kobielski A, Sokal J, Krakos M, Accuracy of sonographic criteria in the decision for surgical treatment in infantile hypertophic pyloric stenosis. Arch Med Sci 2011;162:3456-9.

9. Haahr P, Nelson JP infantile hypertrophic pyloric stenosis: A 25 year study from country of vibrog. Ugeskt Laeger 2000;162:3436-9.

10. Keller H, Waldmann D, Greiner P, Comparison of preoperative sonography with intraoperative findings in congenital hypertrophic pyloric stenosis. J Pediatr surg 1987;22:950-2.

11. Ito S, Tamaru K, Nagae I, Yagyu M, Tanabe Y, Aoki T. Ultrasonographic diagnosis criteria using scoring for hypertrophic pyloric stenosis. J pediatr surg 2000. 35:1714-8 